12

\title{
Оценка жизнеспособности живых тканевых эквивалентов под действием импульсного тока со смещением
}

\author{
(C) Е.А. Шершунова ${ }^{1}$, И.Е. Ребров ${ }^{1}$, В.В. Мищенко ${ }^{2}$, А.И. Крюков ${ }^{2}$, Е.А. Воротеляк ${ }^{3}$, О.С. Роговая ${ }^{3}$ \\ ${ }^{1}$ Институт электрофизики и электроэнергетики РАН, Санкт-Петербург, Россия \\ ${ }^{2}$ Научно-исследовательский клинический институт оториноларингологии \\ им. Л.И. Свержевского, Москва, Россия \\ ${ }^{3}$ Институт биологии развития им. Н.К. Кольцова РАН, Москва, Россия \\ E-mail:eshershunova@ieeras.ru
}

Поступило в Редакцию 29 октября 2020 г.

В окончательной редакции 9 февраля 2021 г.

Принято к публикации 2 апреля 2021 г.

Описана электрофизическая установка для комплексного электропоративного ионофоретического воздействия на биологические мембраны. Приведены результаты оценки жизнеспособности клеток живых тканевых эквивалентов под воздействием источника импульсного тока со смещением. Получены значения электрофизических параметров импульса, при которых сохраняется жизнеспособность клеток в образцах живых тканевых эквивалентов. Полученные данные дают основание полагать, что подобные электрофизические параметры можно использовать при введении лекарственных препаратов через эквивалент мембраны круглого окна улитки и создать технологию введения лекарственных препаратов через биологические барьеры с возможностью их проникновения во внутреннее ухо с применением импульсных электрических установок.

Ключевые слова: импульсный ток, биологические мембраны, жизнеспособность клеток.

DOI: 10.21883/PJTF.2021.13.51117.18606

Лечение негнойной патологии внутреннего уха с помощью фармакотерапии широко используется в клинической практике и применимо для таких заболеваний, как лабиринтит, тиннитус, нейросенсорная тугоухость, болезнь Меньера, отосклероз [1]. Его эффективность во многом обусловлена биодоступностью препаратов в лабиринте внутреннего уха для волосковых клеток кортиевого органа. Традиционные методы доставки лекарственных препаратов (пероральные, транскутанные) имеют низкую эффективность, вызывают значительные побочные эффекты [2]. Интратимпанальные методы не обеспечивают достаточную концентрацию препарата вследствие медленной скорости его диффузии из среднего во внутреннее ухо из-за наличия биомембран, а интралабиринтные посредством инъекции препарата через мембрану круглого окна могут привести к потере слуха, инфицированию отделов внутреннего уха с распространением инфекции на мозговые оболочки [3].

Bсе это подтверждает необходимость разработки эффективных методов адресной доставки лекарственных препаратов без разрушения биологических барьеров для сохранения и восстановления пострадавшей функции внутреннего уха [4-6]. Одним из неинвазивных способов введения препаратов является ионофорез - индуцированная миграция заряженных молекул малой и средней молекулярной массы под действием постоянного электрического поля [7]. Этот метод широко используется в медицине, когда в качестве мембраны выступает кожа [8] с наличием естественных каналов (волосяных каналов и потовых протоков). Проникновение веществ через мембраны без наличия таких каналов доставки, к которым относится и мембрана круглого окна улитки внутреннего уха, может быть реализовано посредством электропорации благодаря увеличению проницаемости биомембраны при воздействии внешнего импульсного электрического поля. Для более эффективной адресной и быстрой доставки лекарств предлагается использовать электрофизическую систему, сочетающую два метода: ионофорез и электропорацию [9,10]. Важным фактором при этом является атравматичность воздействия индуцированной диффузии на клетки мембраны круглого окна. В связи с этим была сформулирована цель настоящей работы - оценить жизнеспособность клеток биологического барьера, эквивалентного мембране круглого окна улитки внутреннего уха человека, при воздействии на него импульсного тока, смещенного относительно нуля.

Для исследования жизнеспособности клеток человека под действием импульсного напряжения создана электрофизическая установка, позволяющая в широком диапазоне изменять частоту, скважность, длительность, амплитуду сигнала, а также уровень его смещения относительно нулевого потенциала. Амплитуда напряжения и ее постоянная составляющая могут варьироваться от $10 \mathrm{~V}$ до $1 \mathrm{kV}$, частота следования импульсов от $1 \mathrm{~Hz}$ до $500 \mathrm{kHz}$ с фронтом нарастания $20 \mathrm{~ns}$ и длительностью импульса от $50 \mathrm{~ns}$ до сотен ms. В качестве аналога мембраны круглого окна улитки в эксперименте были использованы живые тканевые эквиваленты (ЖТЭ) в форме дисков диаметром $1 \mathrm{~cm}$ и толщиной $0.5 \mathrm{~mm}$, состоящие из биосовместимой мембраны с клетками 


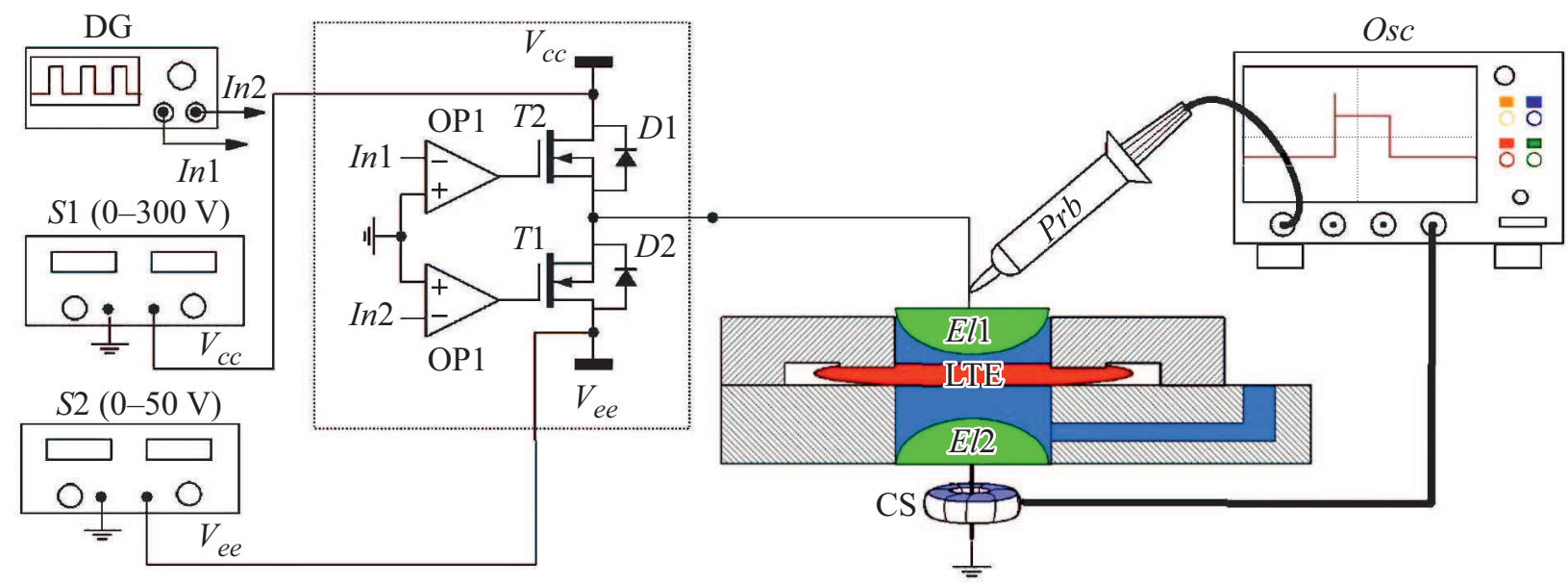

Рис. 1. Схема экспериментальной установки. DG - задающий генератор, $S 1$ - регулируемый источник постоянного напряжения, определяющий амплитуду импульсов, $S 2$ - источник напряжения смещения, CS - токовый пробник, El1, 2 - электроды ячейки, $\operatorname{Prb}$ - высоковольтный щуп, Osc - осциллограф, LTE - живой тканевой эквивалент.

кожи человека (кератиноцитами и мезенхимными стволовыми клетками (МСК)), выращенными на ее поверхности. В качестве электролита, контактирующего с эквивалентом мембраны круглого окна, использовался $0.9 \%$ водный раствор хлорида натрия $(\mathrm{NaCl})$, так как он является основой раствора многих лекарственных препаратов.

Схема экспериментальной установки для комплексного воздействия представлена на рис. 1. Установка состоит из высоковольтного твердотельного коммутатора, регулируемого источника напряжения для формирования постоянного смещения $S 2$, перестраиваемого высоковольтного источника $S 1$, устанавливающего амплитуду импульсов, генератора тактовой частоты $\mathrm{DG}$, ячейки с интегрированными $\mathrm{Ag} / \mathrm{AgCl}$-электродами $(E l 1, E l 2)$, заполненной физиологическим раствором и закрепленным в ней образцом ЖТЭ (LTE). Ячейка имеет вход, через который физиологический раствор подается на нижний электрод и гарантирует контакт с ним и ЖТЭ. Измерения напряжения на ячейке и тока через мембрану осуществлялись пробниками Tektronix P6015A и Tektronix TCP202 соответственно. Регистрация сигналов велась на цифровом осциллографе LeCroy WaveRunner 104Xi-a.

Импульсный генератор выполнен на основе полумостовой схемы с гальванической развязкой и независимым управлением верхними и нижним ключами $[11,12]$. В качестве высоковольтного коммутатора использовались $\mathrm{SiC}$-транзисторы C2M0040120D с рабочим напряжением $1200 \mathrm{~V}$. Благодаря наличию двух источников питания можно контролировать напряжение и ток на двух блоках установки - ионофореза и электропорации. Формирование высоковольтных прямоугольных импульсов происходит путем коммутации транзистором $T 2$ (рис. 1) напряжения $V_{c c}$ от источника питания $S 1$ на верхний электрод $E l_{1}$ установки. $T 1$ при этом находится в закрытом состоянии. Параметры импульса контролируются сигналами $\operatorname{In} 1, \operatorname{In} 2$ с генератора DG. После окончания импульса транзисторы изменяют свое состояние ( $T 2$ закрывается, а $T 1$ открывается), и потенциал электрода сравнивается с ионофоретическим потенциалом $V_{e e}$ источника питания $S 2$.

Электродная ячейка выполнена из АБС-пластика на 3D-принтере из двух частей (нижняя часть представлена на рис. 2,a) с интегрированными посеребренными ЭКГ-электродами. В качестве биологического барьера выступал ЖТЭ с конфлюэнтным слоем кератиноцитов и МСК человека на коллаген-гиалуроновой мембране. Образец ЖТЭ помещался в электродную ячейку и зажимался между двумя ее частями по краю, при этом между электродами и биологической тканью оставался зазор, заполняемый $0.9 \% \mathrm{NaCl}$.

Верхняя электродная ячейка подключалась к выходу импульсного генератора, нижняя заземлялась. На источниках питания устанавливались напряжение смещения $V_{d c}=0-140 \mathrm{~V}$ и амплитуда импульсного напряжения $V_{p}=200 \mathrm{~V}$. Это эквивалентно постоянному току смещения от $0-1.1 \mathrm{~mA}$ и импульсному $1.5 \mathrm{~mA}$. Типичная форма тока показана на рис. $2, b$. Поскольку основными факторами, по которым может быть проведена оценка воздействия ионофореза и электропорации на живые ткани, являются плотность тока и суммарный прошедший заряд, напряжение подбиралось с учетом сопротивления ЖТЭ порядка $100 \mathrm{k} \Omega$ для установки требуемых значений тока $0.1,0.5$ и $1 \mathrm{~mA}$. Длительность ионофоретического импульса составляла $1 \mathrm{~ms}$, частота 

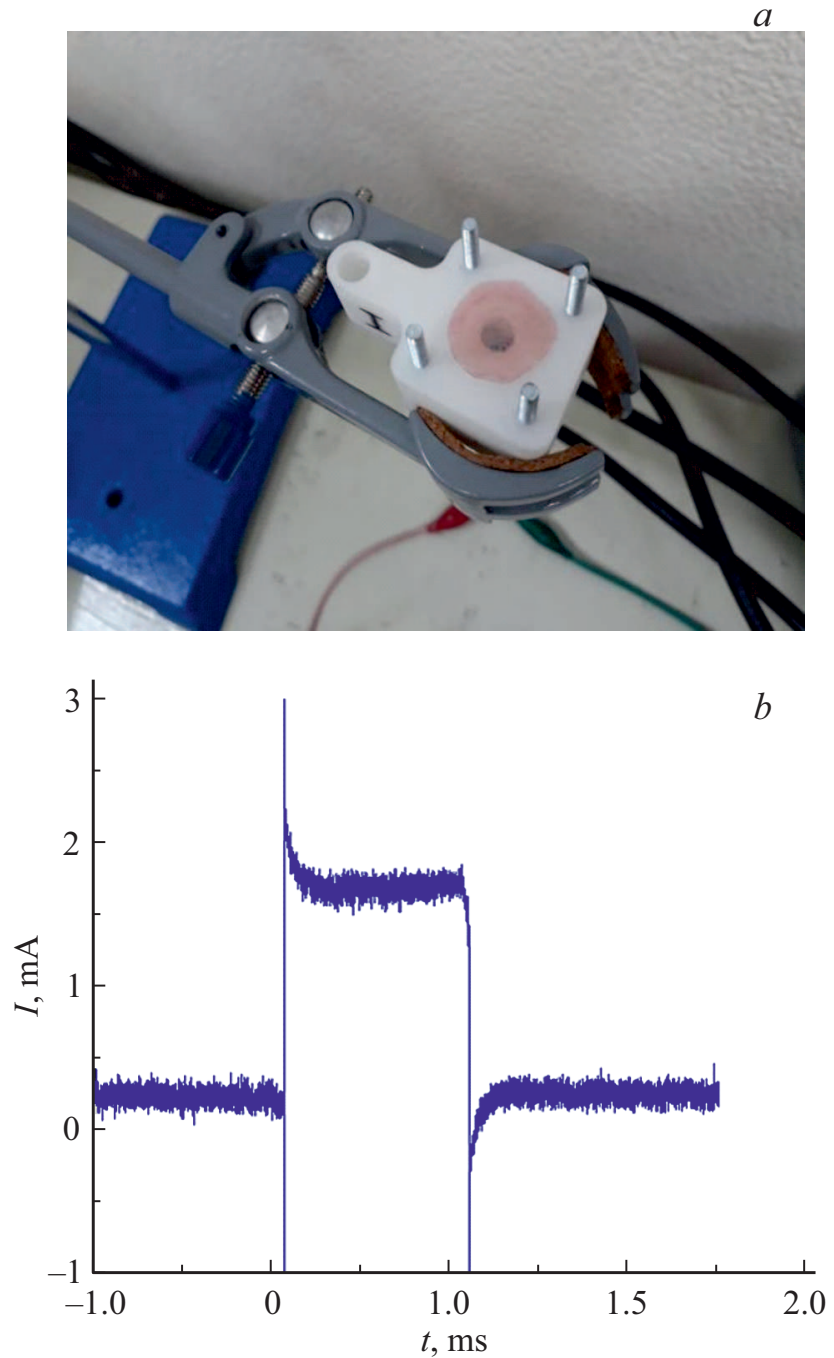

Рис. 2. $a-$ фотография ЖТЭ в электродной ячейке (без верхнего электрода), $b$ - типичная осциллограмма импульсного тока в процессе воздействия.

следования $100 \mathrm{~Hz}$. Время воздействия определялось на основании прошедшего заряда $(0.9 \mathrm{C})$ и таким образом составляло $15 \mathrm{~min}$ при токе $1 \mathrm{~mA}$ и $2.5 \mathrm{~h}$ при $0.1 \mathrm{~mA}$.

Подготовка ЖТЭ представляла собой выращивание кератиноцитов и МСК человека на поверхности коллаген-гиалуроновой мембраны. Клетки человека, используемые в эксперименте, были получены из Коллекции клеточных культур ИБР РАН: в качестве стромального компонента ЖТЭ использовались МСК, в качестве эпидермального - кератиноциты человека линии НаСаТ. Клетки были посеяны на поверхность коллаген-гиалуроновой мембраны стандартным способом в концентрации 30 и $100 \mathrm{~cm}^{-2}$ соответственно. Культивирование ЖТЭ проводилось в течение трех суток в питательной среде DMEM/F-12 (ПанЭко, Россия) с добавлением 10\% FBS (HyClon, США), $2 \mu \mathrm{M} 5$ глутамина и $5 \mu \mathrm{g} / \mathrm{ml}$ инсулина (Sigma-Aldrich, США),
$5 \mu \mathrm{g} / \mathrm{ml}$ трансферрина (Sigma-Aldrich, США) в условиях $\mathrm{CO}_{2}$-инкубатора $\left(37^{\circ} \mathrm{C}, 5 \% \mathrm{CO}_{2}\right)$.

Для выявления жизнеспособных клеток ЖТЭ образцы окрашивались витальным интеркалирующим красителем Calcein AM (Biotium, США) по стандартной методике [13]. При этом в живых клетках Calcein AM флуоресцирует в зеленой области спектра, в то время как в погибших клетках свечение не обнаруживается. Фотосьемка производилась с помощью цифрового флуоресцентного инвертированного микроскопа Olympus при увеличениях $\times 4, \times 20$. Для контроля использовались помещенные в ячейки экспериментальной установки образцы ЖТЭ без воздействия импульсного напряжения. Пример фотографии окрашенного образца ЖТЭ после воздействия на него тока амплитудой $0.1 \mathrm{~mA}$ показан на рис. 3, $a$. На фотографии ЖТЭ видны яркие зеленые
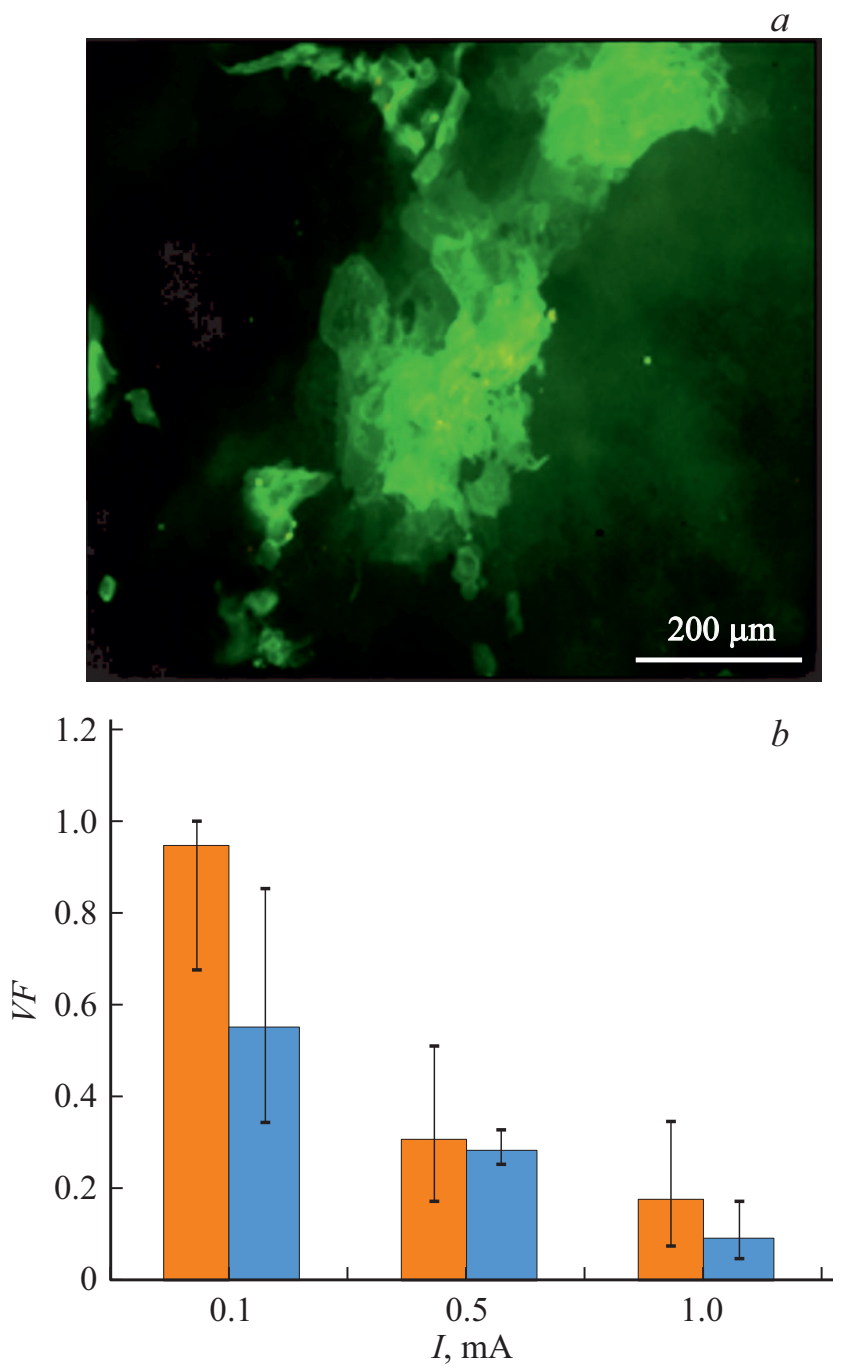

Рис. 3. $a-$ живые клетки в центральной части ЖТЭ с Calcein AM (зеленое окрашивание, см. электронную версию статьи) для тока $0.1 \mathrm{~mA} ; b-$ зависимость жизнеспособности ЖТЭ по центру (левый столбик) и на краю (правый столбик) от амплитуды тока через мембрану ЖТЭ. 
пятна (см. электронную версию статьи), что качественно указывает на наличие живых клеток в этих областях.

Расчет жизнеспособности $(V F)$ клеток проводился по формуле

$$
V F=\frac{O D_{e}-O D_{m}}{O D_{c}} \cdot 100,
$$

где $O D_{e}-$ оптическая плотность в экспериментальных сериях, $O D_{m}$ - оптическая плотность в лунках со средой, $O D_{c}$ - оптическая плотность контрольных образцов.

В результате проведенных экспериментов было выявлено, что количество жизнеспособных клеток в составе ЖТЭ изменяется в зависимости от амплитуды тока (рис. 3). Характер зависимости одинаков как для центральной части образцов, так и по краям мембран. Слабая жизнеспособность клеток по краям экспериментальных образцов связана с особенностями их фиксации, компрессией краями электродной ячейки. Как видно из рис. $3, b$, наибольшая жизнеспособность клеток наблюдается при токах менее $0.5 \mathrm{~mA}$. С увеличением тока жизнеспособность падает и доходит до значения $0.2 \pm 0.1$ при $1 \mathrm{~mA}$.

На примере ЖТЭ показано, что созданная электрофизическая установка может быть использована для воздействия на биомембраны без их деструкции в определенном диапазоне выходных токов. Так, жизнеспособность клеток в эквивалентах толщиной $0.5 \mathrm{~mm}$ падает с ростом амплитуды тока и составляет $0.2 \pm 0.1$ при токе в $1 \mathrm{~mA}$. Мы предполагаем, что полученные результаты будут способствовать созданию технологии введения лекарственных препаратов во внутреннее ухо через биологические барьеры без естественных каналов благодаря применению импульсных электрических установок, оказывающих электропоративно-ионофоретический эффект.

Настоящая статья не содержит каких-либо исследований с участием людей в качестве объектов исследований.

\section{Финансирование работы}

Исследование выполнено при поддержке Министерства науки и высшего образования РФ в рамках тем госзадания № 0057-2019-0005 и 0088-2021-0016.

\section{Конфликт интересов}

Авторы заявляют, что у них нет конфликта интересов.

\section{Список литературы}

[1] Н.Л. Кунельская, РМЖ, 19 (24), 1478 (2011).

[2] M.R. Prausnitz, S. Mitragotri, R. Langer, Nature Rev. Drug Discov., 3 (2), 115 (2004).

[3] А.И. Крюков, Н.Л. Кунельская, Е.А. Шершунова, И.Е. Ребров, В.А. Ямщиков, Е.В. Гаров, В.В. Мищенко, Вестн. оторинол., 84 (5), 6 (2019). DOI: 10.17116/otorino2019840516

[4] H.Y. Thong, H. Zhai, H.I. Maibach, Skin Pharm. Phys., 20 (6), 272 (2007). DOI: 10.1159/000107575
[5] A. Samad, Y. Sultana, M. Aqil, Current Drug Delivery, 4 (4), 297 (2007)

[6] M. Kumar, J. Pharm. Pharm. Sci., 3 (2), 234 (2000).

[7] P.G. Green, J. Control. Release, 41 (1-2), 33 (1996).

[8] B. Das Kurmi, P. Tekchandani, R. Paliwal, S. Rai Paliwal, Current Drug Metabolism, 18 (5), 481 (2017).

[9] G.A. Hofmann, L.J. Crandell, Electroporation and iontophoresis apparatus and method for insertion of drugs and genes into cells. Patent US5507724A (Washington, DC, 1996).

[10] T.B. Napotnik, M. Reberšek, T. Kotnik, E. Lebrasseur, G. Cabodevila, D. Miklavčič, Med. Biol. Eng. Comp., 48 (5), 407 (2010). DOI: 10.1007/s11517-010-0599-9

[11] С.И. Мошкунов, В.Ю. Хомич, Е.А. Шершунова, Письма в ЖТФ, 45 (3), 34 (2019). DOI: 10.21883 /PJTF.2019.03.47270.17528

[12] С.И. Мошкунов, И.Е. Ребров, В.Ю. Хомич, Е.А. Шершунова, ПТЭ, № 6, 62 (2018). DOI: $10.1134 / \mathrm{S} 0032816218050257$

[13] Д.Я. Алейник, Е.В. Загайнова, М.Н. Егорихина, И.Н. Чарыкова, О.С. Роговая, Ю.П. Рубцова, А.Н. Попова, Е.А. Воротеляк, Соврем. технологии в медицине, 11 (4), 34 (2019). DOI: $10.17691 / \mathrm{stm} 2019.11 .4 .04$ 